\title{
Can Prevention Programs Work Together? An Example of School- based Mental Health with Prevention Initiatives
}

\author{
Hank Bohanon \\ Loyola University Chicago, hbohano@luc.edu \\ Meng-Jia Wu \\ Loyola University of Chicago, mwu2@luc.edu
}

Follow this and additional works at: https://ecommons.luc.edu/education_facpubs

Part of the Educational Assessment, Evaluation, and Research Commons, and the Special Education and Teaching Commons

\section{Recommended Citation}

Bohanon, H., \& Wu, M.-J. (2011). Can prevention programs work together? An example of school-based mental health with prevention initiatives. Advances in School Mental Health Promotion, 4(4), 35-46.

This Article is brought to you for free and open access by the Faculty Publications and Other Works by Department at Loyola eCommons. It has been accepted for inclusion in Education: School of Education Faculty Publications and Other Works by an authorized administrator of Loyola eCommons. For more information, please contact ecommons@luc.edu. c) $($ ())

This work is licensed under a Creative Commons Attribution-Noncommercial-No Derivative Works 3.0 License. Copyright @ 2011 The Clifford Beers Foundation \& University of Maryland 
Hank Bohanon

Meng-Jia Wu

Loyola University of Chicago, USA
Can Prevention Programs Work Together? An Example of School-based Mental Health with Prevention Initiatives
Key words: positive behavior support; response to intervention; school-based mental health social and emotional learning; integration

\section{Introduction}

Schools are facing increasing demands to address the mental health needs of their students (Foster et al, 2005). Evidenced-based practices (EBP), including school-based social and emotional learning programs, can lead to improved outcomes to address these needs (Durlak ef al, 2011). Successful implementation of prevention programs may especially improve outcomes for students at risk of failure. Without these supports, these students may be likely to develop more involved diagnoses in the fufure (Costello, 2003). However, training school staff in EBPs is not enough to ensure success of implementation (Langley et al, 2011). Implementation of school-based programs to address mental health care for students can be affecied by issues such as the personal attifudes of the staff, treatment fidelity, and on-going collaboration between partners (such as families, schools and mental health partners; Fiks \& Leslie, 2010).

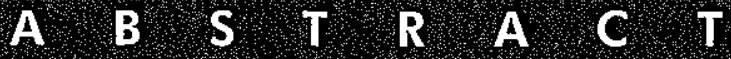

Personnel addressing mental bealth in schools are required to provide supports in settings that have decreasing resources and multiple initiatives. While competing initiatives in schools can pose problems, integration of prevention systems and data may lead to more efficient supports and effective outcomes. Mental health service providers must consider how integration of schoolwide initiatives such as positive bebavior interventions and supports (PBIS), response to intervention (RTI), and social and emotional learning (SEL) can improve their work. This article provides an example showing varying levels of integration of schoolwide models in one state. It will include the level of integration of schoolwide supports with school-based mental health (SBMH), the relationship between integration of schoolwide practices and reported implementation, and the relationship between schoolwide practices and outcome data related to SBMH. Suggestions for integrating models effectively and using data to improve collaboration will be provided. 
To address issues of implementation, practitioners may need to consider systems factors (for example organizational structures or administrative support) beyond the EBPs themselves (Langley et al, 2011). As described below, these factors should be considered across models of support for students. If EBPs can be infegrated with other, existing school reform models that address system-level issues, the preventative nature of school environments might improve (Bohanon \& Wu, 2011). Needless to say, schools may already be required to address separate issues related to academic, behavioral, social, and emotional supports due, in part, to different policies and technical assistance provision as described later in the example in this study. If is important to be able to integrate the strengths of each approach for the benefit of all students in a more efficient way.

While EBPs have unique components, depending on their purpose, the systems requirements for interventions can be similar (Bohanon \& Wu, 2011). The purpose of this paper is discuss a theoretical framework for integration of multiple-tiered school-based models, and provide an example in school contexts showing how approaches to supporting students have converged. We begin with an introduction to three-tiered reform models being adopted by schools that enhance student success in one state. The overlap between these systems will be discussed, followed by a case example of the status of integrating these systems. The immediate effects of integration will be discussed, followed by the limitations on examining the effects in current systems.

\section{Tiered models for addressing student needs}

There are many approaches to addressing improvement of outcomes for students. For the purpose of this paper, we focus on models based on tiers of support (Walker et al, 1996) that address academic, behavior, social and emotional outcomes being implemented in a Midwestern state.

There appears to be some connection between academic, behavioral, social, emotional, and mental health outcomes, although the causal relationships between variables such as academic and behavioral outcomes have not been firmly established (Algozzine et al, 2011). For example, Welsh and colleagues (2001) found that academic achievement was related to social competence for individuals moving from first to second grade, and from second to third grade. They also found that social competence was related to academic achievement for students moving from second to third grade. Improved standardized test scores have been associated with high levels of student bonding with the school, and improved social and emotional decision making (Fleming et al, 2005). Schools with higher levels of implementation of preventative behavior support strategies have recognized decreases in office discipline referrals (a typical outcome measure for behavior; ODRs) and improved academic test scores (Bradshaw et al, 2010; Horner et al, 2009; Lassen ef al, 2006).

These connections have a bearing on the importance of the infegration of models of support. In order to demonstrate long-term benefits for sfudents, models should be selected according to the specific goals of teams (Kahne et al, 2008), and school staff should use outcome data at varying levels depending on the type of support selected (Lueck \& Kelly, 2010) to address specific areas of concern effectively.

\section{Three-tiered approaches}

This project focuses on three-tiered models designed to enhance student outcomes related to SBMH. These approaches included PBIS, RTI, and SEL. Typically, these three-tiered models involve primary (for example entire school receives the support), secondary (for example specified groups of students receive support), and tertiary support (for example individual student receives support) (Walker et al, 1996). Applied research in these areas of support has ranged from school- to community-based interventions (Walker, 2010). These processes include supports that are designed to prevent problems, alert adults when problems are occurring, and respond to students who require more intensive intervention. Each of these approaches has specific systems, practices, data, and outcomes. The system components in particular may be related to successfully implementation of EBPs to improve student mental health (Forman ef al, 2009).

\section{Common systems, practices, data, and outcomes}

Forman and colleagues (2009) identified the following key areas to address to increase effective implementation and sustainability of evidenced-based interventions:

a development of support from the administration

obtaining support from teachers

obtaining financial resources to sustain the project

- providing effective training and coaching to increase fidelity 
alignment of the interventions with the school's goals, philosophy, policies, and programs

(1) making sure that program outcomes are visible to all stakeholders

developing processes to address change in staff and administrators.

Tiered models related to SBMH (such as RTI) could be catalysts for implementing SBMH EBPs because they inherently include these system requirements.

\section{Overview of systems of support}

Specific components of three-tiered models appear to be related to SBMH. These elements are necessary for carrying out EBPs successfully in school settings, but are not necessarily the practices themselves. They include:

a general focus on prevention

whe commitment of local administration and leadership

a practices, programs, and policies that are shared by stakeholders

- strong school teams that are representative of school settings

ongoing support for implementation efforts (such as funding, coaching or training)

- data-driven decision making

access for all stakeholders (such as families and students) to all tiers of support

- tiers that represent interventions, nof students (for example not referring to a student as a tier-three individual)

- culturally relevant programs and approaches (Lueck \& Kelly, 2010).

Key components of implementation include explicit and shared measurable goals, an effective identification and/or referral process for identifying students in need of support and connecting them with EBPs, and systemlevel commitments (for example leadership participation, district and schoolwide support) (Lueck \& Kelly, 2010). These components are among the key systems, data, and outcomes of other three-tiered approaches such as PBIS, RTI, and SEL.

At the systems level, PBIS, RTI, and SEL share commonalities such as the need for administrative support, leadership teams with specific roles to guide implementation, audits of current practices and data tools, and commitment of the staff to the desired change
(Elias et al, 2003; Kurns \& Tilly, 2008; Sugai et al, 2010). At practice level these three initiatives include instructional strategies that increase engagement (Simonsen et al, 2008; Walberg et al, 2004), use of effective instruction (such as opportunities to respond and participate; Kurns \& Tilly, 2008), and a focus on increasing students' ability to regulate their own behaviors. While all three strategies can be aligned with standards of practice, only SEL (the State of Illinois Standard for SEL) and RTI (for example state instructional standards) are directly connected to specific standards. These components are not unique programs, but systems requirements that may be necessary for successful implementation of EBPs.

Data and outcomes for all three approaches can include use of office discipline referrals (ODRs), curriculumbased measures (CBM), performance and standardized assessments, changes in perceptions of safety, and attitudes to school connection. The differences between these approaches relate to whether the implementers considered an outcome (such as ODRs) as proximal or distal. All tiered models, including SBMH, are connected to some type of self-assessment or measure of fidelity for implementation (for example RTI, Self-Assessment of Problem Solving Implementation (SAPSI), Doorman \& Castillo, 2011; PBIS, Effective Behavior Support SelfAssessment Survey (SAS), Sofran, 2006; SEL, Collaborative for Academic, Social, and Emotional Learning (CASEL) Rubric; SMH, School Mental Health Capacity Instrument, Feigenberg et $a l, 2010$ ). These instruments may be useful for development of action plans and for determining the level of fidelity of implementation.

A concern about use of combined models, when not integrated, is that each system might require separate fidelity instruments, teams, and action plans. There would also appear to be a need to have shared outcomes to guide the integration of these approaches, including use of interwoven strategies (McIntosh et al, 2010) to address the academic, social, behavioral, and mental health needs of all students, use of integrated models that promote learning and mental health, focusing on improving outcomes for all students including those with emotional and behavioral disorders, and increasing active participation of parents in the school experience (Ałkins, 2010).

\section{How systems can support one another.}

Together, PBIS, RTI, SBMH, and SEL could have higher levels of efficacy in addressing the needs of all students 
than if they are implemented separately. The following section provides a theorefical framework for integration of systems, practices, data, and outcomes when addressing student needs.

\section{Strengths of systems, practices, data, and outcomes to address needs}

In the field of information technology, the phrase 'depth in defense' is used to describe layers of prevention that head off vulnerabilities to systems (for example firewalls and strong passwords). An axiom of this concept is that no one layer is an effective deterrent for all potential threats to the health of a system; multiple layers of integrated prevention can provide more protection than any one on its own (Lippmann ef al, 2011). Within models of tiered intervention, work must focus on effective core curriculum and remediation insfruction, identifying students who are not responding to this core, determining whether addifional supports are needed, and evaluating student progress (Kurns \& Tilly, 2008). Instruction and support should be based on a common core that addresses learning, behavioral, social, and mental health outcomes for students. Combined schoolwide and district-level teams should ask professional learning community (PLC) related questions about the focus of their work (Dufour ef al, 2004). These questions should include:

what do we want all students to know and be able to do academically, behaviorally, socially, and emotionally?

a how will we know whether students are developing the aforementioned skills?

how will we respond when students are not developing these skills in all domains?

Core matrices would have to be developed and aligned with standards and competencies that students need for success in school settings related to academics, behavior, social and emotional learning, and mental health (Bohanon \& Wu, 2011). School teams may require access to data that highlight the level of school connection, to develop a sense of urgency that student wellness needs to be addressed (Kotter, 1995). Staff who typically implement SBMH approaches for individual students (for example social workers) may be more effective at addressing issues related to internalizing behaviors (such as depression), while other school team members (such as behavior specialists) may be more effective at addressing externalizing behaviors (such as violence and aggression).

While long-term outcomes (scores on standardized test, for example) can and should be addressed in SBMH-related interventions, there may be a need for more immediate measures related to the performance of students expected by teachers (Franklin et al, 2009), such as use of General Outcome Measures (GOM), an essential component of the RTI Process. These GOMs are data that are associated with outcomes that society has deemed important. For social behaviors, GOMs can include the ability of students to exhibit behaviors that are required by law or are specific to certain settings (codes of conduct, for example). When GOMs are measured across time, they can provide estimates of student progress as changes to the school environment are made (Riley-Tillman ef al, 2011). When staff implement SBMH approaches combined with PBIS, RTI, and SEL, they potentially have access to more useful GOMs (for example curriculum-based measures (CBMs), office disciplinary referrals (ODRs), or screening data related to student-school connection). Access to these combined datasets would perhaps lead to improved well-being of children by enhancing staff's ability to integrate and evaluate EBPs (Durlak et al, 2011).

Asking questions such as what we want all students to know and be able to do would be key to selecting screening measures (for example identify purpose of the data; Dowdy et al, 2010). Teams could ask what they want all students to know and be able to do academically, socially, emotionally, and behaviorally. Identifying needs and useful EBPs (Dowdy et al, 2010) could then be related to the PLC questions, such as how we will know whether students meet the expectations, and what we will do if they do not. The basic systems components of tiered approaches provide a crucial framework. The PLC approach could guide the integration of practices, data, and outcomes.

\section{An example}

This example illustrates the status of schools integrating SBMH with PBIS, RTI, and SEL in one state. The details of one school's combined systems are also discussed, and the qualitative data were analyzed using a case study format (Scott, 2001) to provide more insight of merging multiple initiatives. The relationship between the combinations of systems being implemented (for example RTI, PBIS) and the types of practice, data, and outcome used by school teams was examined. The hypothesis 
of this project was that there would be a relationship between the combinations of systems being implemented (RTI, PBIS) and the types of practice, data, and outcome used by school teams. The school examples were selected by purposeful sampling since they were included in a large statewide project. Specifically, schools with key features of the subject of the study (such as integration of tiered interventions; Patton, 1980) were included.

\section{Background}

The data for this study were collected as a result of a statewide evaluation project related to SBMH funded by the state's department of human services. The state in which this study was conducted, in the upper Midwest, had passed legislation that encouraged development of SBMH. The purpose of this policy was to promote mental health prevention systems and early-intervention services. Schools in this project were required to develop programs that served the behavioral and physical health needs of their students. They were encouraged to attempt to address the health choices of their students and address other health concerns using evidence-based approaches. The process at each building was guided by a school-based advisory feam that was representative of the local community. More than 60 schools were chosen to participate in the project. The evaluation of the study was guided by a partnership supported by the state's mental health act, and included personnel from the department of human services, the state board of education, community agencies, and universities.

\section{Data collection}

A data protocol, the primary collection instruction for this project, was completed by the team leaders from each school supported by the SBMH grant. The tool was based on the specific evaluation questions of the project. The instrument required schools to provide data on their implementation of multiple tiers of intervention, integration of SBMH with other state-supported initiatives, and steps taken by teams towards sustainability.

The instrument was integrated into an online data system that allowed participants to submit data through a web portal in the months of October, January, April, and July of AYO9-10. Online training for data entry was provided to participants, and was available asynchronously in streaming format which included video examples of data entry. The school team leaders were supported in data collection by an evaluation coordinator through email, phone calls, and web-based conferencing. To provide the most up-to-date information, only data from the latest data collection points (April and July $2010)$ were used in the analysis in this example.

\section{Results}

A total of 61 schools (63.9\% elementary schools, $19.7 \%$ middle/junior high schools, and $11.5 \%$ high schools) were included in this analysis. The enrollment for these schools ranged from 100 to 976 students in 2009. On average $64.4 \%$ of students were Caucasian, $16.3 \%$ were Hispanic, and $9.6 \%$ were African American. The percentages of students with low socio-economic status ranged from $0.4 \%$ to $88.6 \%$, with a median of $33.4 \%$. The attendance rate ranged from $87.9 \%$ to $98.5 \%$, with a median of $95.6 \%$.

\section{Status of intervention (AY09-10 school year)}

Table 1, below, provides a breakdown of the combinations of models that were being implemented by school staff. The approaches studied in this project included PBIS, a state-supported RTI pilot project, SBMH, and SEL. The majority of the sites in this sample were implementing SBMH in combination with other processes. Combinations with the highest percentage of schools reporting implementation involved SBMH with PBIS and SEL IN $=23,38 \%$ ).

Table 1 also includes information on the number of schools by combinations of models that were using

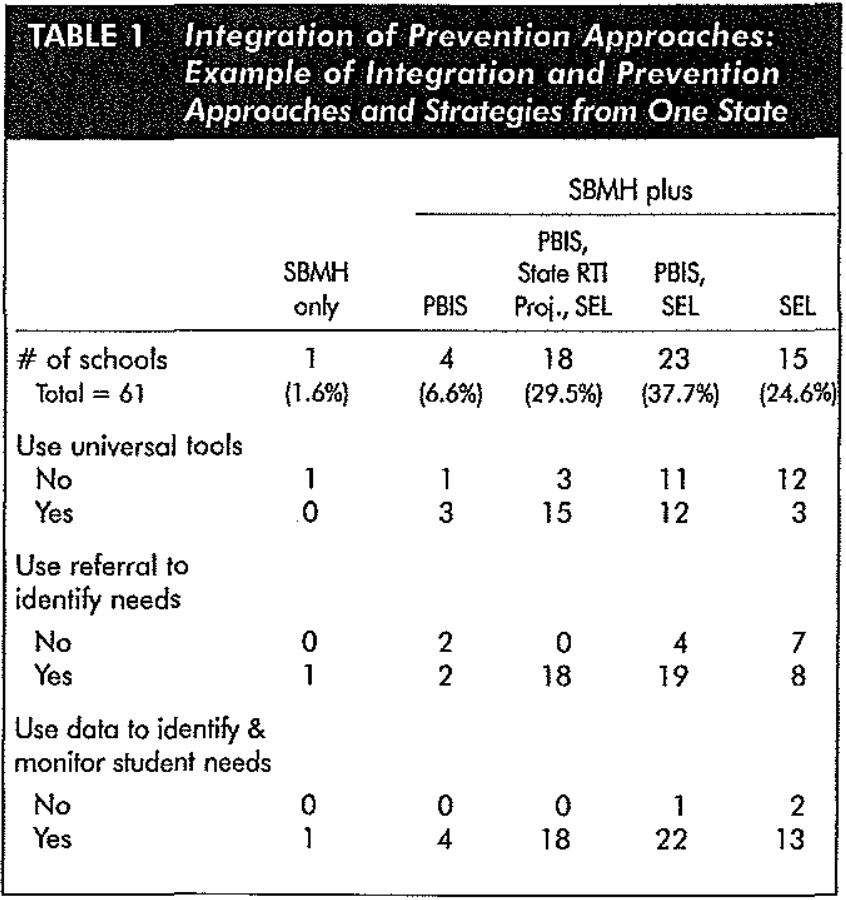


universal screening tools, a referral system to identify students in need of more support, and data to identify students in need of support and to monitor their progress. For the purposes of the evaluation of this project, universal screening tools were defined as universal efforts using agreed instruments, methodology and protocols to identify students exposed to or at risk of school failure or of psychological, emotional or behavioral problems. Referral systems were defined as a process (for example a form) used by staff to identify student for early intervention services. Progress monitoring was defined as the process of using data to measure change at student, family, classroom, schoolwide, systemwide and/or community level. The greatest percentage of schools reporting use of universal screening tools were implementing SBMH with PBIS, the state RTI project, and SEL ( $N=15,25 \%)$. With regard to referral systems for identifying needs, the schools reporting the most use were implementing SBMH with PBIS and SEL $N=$ $19,31 \%$ ). Schools that were implementing SBMH with PBIS and SEL $(N=22,36 \%)$ reported making the most use of data to monitor progress on student needs. Combined use of models of support may have strengthened school teams' abilities to use universal screening and monitoring of progress in conjunction with their EBPs. Overall, the schools did not appear to be implementing $\mathrm{SBMH}$ in isolation. Screening and referral processes are core components of many of the other three-tiered models.

While in some cases there were no major differences between the combinations of approaches (for example using data to monitor progress), there appeared to be some relationships between clusters of models and the degree to which schools reported use of intervention practices. A significant relationship was identified between use of universal tools and types of intervention used by the schools $\left(x^{2}=15.14, d f=4, p=.004\right)$. Schools that used more combinations of interventions (for example PBIS, RTI, and SEL) tended to use universal screening tools. The most significant difference was observed between schools using SBMH with PBIS, RTI and SEL, and schools using SBMH and SEL only. The odds for using universal tools was 20 times as large for schools with more initiatives combined as for those with fewer (Odds ratio $=(15 / 3) /(3 / 12)=20)$. This would mean that if schools were implementing other three-tiered initiatives, they would perhaps have greater access to universal data for decision making (determining quality of the core, identifying students in need of further support, for instance). A significant relationship was identified between use of referral processes and the types of intervention implemented $\chi^{2}=13.07, d f=4$, $p=.011)$. All 18 schools using SBMH with PBIS, RTI, and SEL used referrals. Access to other three-tiered models might have provided additional support for teams to use referral data for identifying students in greater need of support. The relationship between use of data and types of intervention could not be tested because several cell counts appear to 0 . Most schools in this sample appeared to use data to identify student needs.

\section{Secondary supports}

Many of the schools included reported interventions that were targeted to groups of students. These interventions included Check In and Check Out, Check and Connect, Teen Parent Conferences, academic instructional groups, Skill Streaming, and Strong Kids Curriculum. Seventeen schools (27.9\%) reported that their students were benefiting from some type of peer mentoring to address problem behavior. Peer mentoring was defined as a process in which a peer shared knowledge, information, skills and/or perspectives in order to support and foster the growth of another student. Thirty-seven $(32.8 \%)$ of the reporting schools said that students were receiving and benefiting from programs involving adult mentoring. An adult mentor was defined as any adult who, through a developmental relationship with a student, shared the knowledge, information, skills or perspectives gained in order to support and foster student growth.

Thirty-seven schools $(60.7 \%)$ stated that teacher consultation about students with individual needs was benefiting students. Teacher consultation for individual students was defined as a discussion or conference between a feacher and a mental health practitioner to share information and suggestions, or to plan classroombased interventions for a single student. Teacher consultations to address issues of class climate were reported to be helping students in $27(37.7 \%)$ of the schools. Teacher consultation to address classroom issues was defined as a discussion or conference between a teacher and a mental health practitioner to share information and suggestions, or to plan for classroombased interventions for a group of studenis or the entire classroom population. At least $26(42.6 \%)$ of the schools reported that students were benefiting from crisis intervention supports. Crisis intervention was defined as time-limited, short-term inferventions designed to restore equilibrium and a level of functioning that existed prior to a disturbing event. The event could 
have been at individual, family, school or community level, but caused significant stress that overwhelmed an individual's ability to cope and solve problems. Students were reported to be benefiting from family supports that connected them with mental health services in 31 reporting schools $(50.8 \%)$. Twenty schools $(32.8 \%)$ reported that students were benefiting from tertiary-level supports. Tertiary supports were defined as referral, case management, and coordination services to ensure that students accessed necessary supports.

\section{Relationship between combinations of interventions and disciplinary outcomes}

Data were available for two disciplinary outcomes (expulsions and suspensions) for the schools included in this example. These data were summative in nature and were reported in July. The number of expulsions during AY09-10 ranged from zero to seven for the 47 schools that had valid expulsion data. Thirty-nine schools (83\%) did not expel any students. Figure 1, below, provides information on percentages of schools with zero expulsions by combinations of supports. As can be seen in Figure 1, the majority of schools in this sample that had zero expulsions during the AY09-10 academic year were implementing combinations of SBMH with PBIS and SEL $(N=16,41 \%)$ or SBMH with PBIS, the state RTI initiative, and SEL ( $N=15,39 \%)$. Considering the number of schools implementing each combination of intervention, schools using SBMH and PBIS combined had a significantly higher percentage of zero expulsions $(z=3.105, p<.001)$. As for suspensions, 44 schools had valid data on the number of students suspended out of the school at least once during AY09-10. Among these schools, the number of suspensions ranged from 0 to $301 ; 13$ schools had zero suspensions. Of these 13 schools, seven were implementing SBMH with PBIS, the state RTI initiative, and SEL, four were implementing SBMH with PBIS and SEL, and two were implementing SBMH with SEL.

\section{A case example of implementation in high school}

Here we provide a case example from a diverse community that was implementing SBMH. The dataset was made up of seven high schools. The drop-out rate in these schools ranged from $0.5 \%$ to $4.4 \%$ (median = $1.8 \%$ ). Graduation rates ranged from $81.2 \%$ to $100.0 \%$ (median $=92.2 \%$ ). We briefly discuss one of the seven high schools.

When we reviewed the specific policies in place to

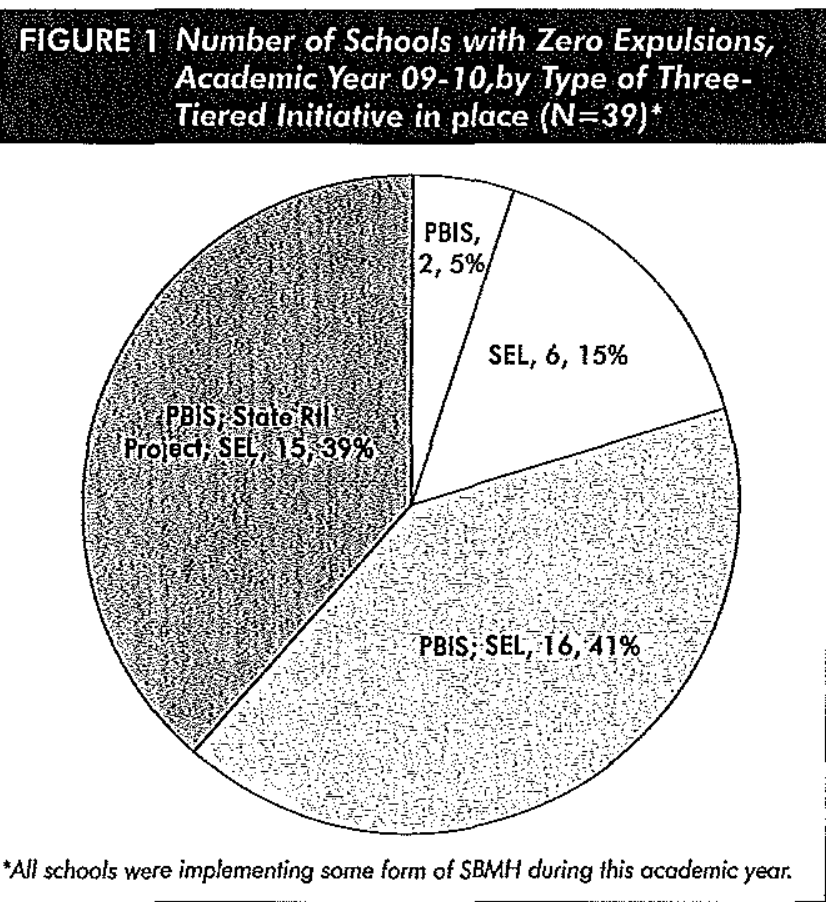

support universal intervention, several themes were identified. This high school was integrating SBMH with PBIS and SEL, and listed several steps to integrate its initiatives. First, the school was implementing schoolwide PBIS, in that expectations were being taught directly. As a function of teaching expected behaviors, schools developed matrices that included specific expectations by location from which they could develop lesson plans. This school had aligned these expectations with SEL standards developed for its state. This school also used SBMH teams and personnel to work directly with their building and core level teams through monthly school improvement meetings. These meetings were designed to address programmatic issues and any other needs related to the primary interventions. While they did not specify that they were working with the state RTI pilot project, the school indicated that it was using RTI coaching support from a local education office. Its universal interventions were guided by a representative team which included individuals from the teaching staff, school social work, school psychology, school administration, parents, and students. For universal screening, the school was using Signs of Suicide (Aseltine, 2004) to identify students who might be at risk of depression and of suicide.

Early interventions teams met every other week in this high school. Early intervention was guided by a representative team which included individuals from the teaching staff, school social work, school psychology, school administration, and parents. The school reported 
that the team met to:

- make data-based decisions to identify students in need of interventions

conduct individualized needs assessments to identify the level of intervention needed

- review evidence informed interventions available in the school to address the students' identified problem

- review available interventions with student, family and student support teams in the school

(1) consider family input in making intervention decisions

implement an evidence-informed intervention

1. evaluate infervention outcomes to determine whether they are having the intended effect

make adjustments to interventions based on outcomes.

In progress monitoring the school reported that the team was using:
pre- and post- intervention questionnaires
rating scales
school aftendance
grade point average
- ODRs
CBM data.

The team also used a referral system to identify students in need of early intervention supports, and reported that they were using the same data both to identify and to monitor progress on students' needs. The team was using targeted interventions such as a program that incorporated technology education for students who were at risk of failure.

\section{Discussion}

The purpose of this paper was to discuss a theoretical framework for integration of multiple-tiered school-based models, and to provide an example of how approaches to supporting students have converged in some school contexts. The paper asked whether there is a relationship between the combinations of systems being implemented (such as RTI and PBIS) and the types of practice, data, and outcome used by school teams. Most schools were implementing SBMH with other tiered models (such as SEL) that focused on behavioral, social, and emotional learning. The state RTI project was included in $30 \%$ of the reporting schools. None of the schools reported implementing the state RTI project and SBMH alone perhaps because the sample was small. These data seem to support, for this example, not only that these schools could implement SBMH with other models, but also that few attempted SBMH without them.

There appeared to be some infegration of SBMH and other models with regard to access and use of data for decision making. The evidence from this study suggests that the schools that were most likely to reporf using universal screening tools for decision making were implementing SBMH with PBIS, the state RTI project, and SEL. If is possible that the overlap of the systems requirements for each of the non-SBMH approaches supported use of screening data for these schools.

As Dowdy and colleagues (2010) state, use of screening data in schools should be guided and interpreted by a defined team of educators and related service professionals within a building. In our experience, some schools that collect screening data on social or emotional learning do not actually use the data for decision making; these data can remain in file drawers or on servers where no-one will see them again. This may occur when dafa are collected and there is no team charged with making decisions about their use. Models such as PBIS, RTI, and SEL encourage development of a schoolwide team to review data and make decisions. The infrastructure provided by these models and the experience of the feams in using screening data may have contributed to the relationship between the combinations of models and use of data in this example.

This study has identified a relationship between the likelihood that schools were using referral systems for support and data for progress monitoring. Again, each of the other non-SBMH approaches encourages use of administrative support, teams, and other processes for each level of support (universal, secondary). There appeared to be a relationship between the likelihood that schools were using referral systems for support and data for progress monitoring. Similar to the reason mentioned above, each of the other non-SBMH models encourages systems supports (for example administrative support or teams) to guide interventions across tiers (Elias et al, 2003; Kurns \& Tilly, 2008; Sugai et al, 2010). These system supports might have increased the likelihood that these schools would use referral practices and progress monitoring to guide their more intensive interventions related to SBMH. There are limited data on the actual fidelity of implementation and the 
reliability of the data used by school teams. However, these data do indicate that schools in this sample that were integrating SBMH with other models were more likely to be using referrals processes and monitoring słudents' responses to intervention.

There seemed to be a wide range of practices to support students who required support beyond universal interventions. Of note was that more than $60 \%$ of the schools reported that their teachers were receiving support regarding the success of their students. As Fiks \& Leslie (2010) said, ongoing collaboration between partners may be a form of support critical to implementing specific EBPs for students effectively. Having multiple models that provided resources for teachers may have increased the possibility that these teachers were receiving support. While we do not know the quality or duration of these consultations, it appears that they would be more likely to occur in the schools that were implementing multiple models with SBMH. Use of SBMH with other models may also have increased the likelihood that supports related to mental health were provided through direct care to students as a part of consultation with teachers. As Franklin and colleagues (2009) point out, people in the mental health field bring a unique set of skills that may be more effective when addressing issues related to internalized behaviors.

One of the contributions of this study is its examination of the effectiveness of practices that use outcome data. Several interesting patterns were identified in these schools regarding disciplinary outcomes (such as expulsions and suspension). All the schools that did not report any expulsions were implementing SBMH with some other type of three-tiered model. Use of PBIS with SBMH was related to a significant relationship between types of model and zero expulsions. As with expulsions, the 13 schools reporting zero suspensions for the school year were implementing SBMH in combination with other models. It is possible that the combined prevention models, through schoolwide approaches (such as teaching locally defined expectations, improving academic and social core curriculum) and supports (such as personnel and EPBs), were related to the decrease in use of suspensions.

Regarding the case study example, there is limited research on three-tiered prevention models and high school settings (Bohanon ef al, in press). This school appeared to enhance its schoolwide model by combining supports. For example, the school incorporated SEL state standards into its behavior core curriculum. From an RTI perspective, this improved the quality of the behavioral core by aligning it with state standards. In ferms of SEL, alignment with PBIS provided a mechanism to teach these skills directly across settings and personnel through a matrix of expectations and lesson planning (Bohanon \& Wu, 2011). The PBIS and SEL components of implementation were enhanced by the presence of staff familiar with mental health-related issues at monthly planning meetings.

The high school in the example was using a variety of early intervention systems, practices, and data to provide early intervention for its students. The school team appeared to be using practices that were designed to respond to student needs (such as reviewing evidenceinformed practices available for students in the schools), and monitoring progress using tools such as rating scales, CBMs, and grade point averages. As Franklin ef al (2009) suggested, schools should use data that are diagnosfic and formative in nature (like GOMs) to make program decisions for students. Access to these data allow school teams to make decisions about supports for students without having to wait for failure. The high school in this example was using several of these GOMs for decision making. It is possible that this school was using data such as rating scales, ODRs, and CBM data as result of the integration of models. Since the school was consulting with an external coach for $R T I$, it is possible that it was in the beginning stages of RTI and had access to CBMs. Access to these GOMs would perhaps enhance the team's ability to identify problems, develop programs or select EPBs, monitor the progress of students, and adjust accordingly.

This project may have a number of implications for practitioners and researches alike. Schools that implement supports for all students should be using outcome data to drive their work (Lueck \& Kelly, 2010). It appears that the schools in this example that were implementing SBMH benefited from having access to other approaches to increase use of outcome data. Processes such as PBIS, RTI, and SEL use outcome data for identifying and monitoring the needs of students (Elias et al, 2003; Kurns \& Tilly, 2008; Sugai ef al, 2010). Integration of SEL standards with PBIS as a host program may have improved the ability of the school team to deliver schoolwide social and emotional support (Bohanon \& Wu, 2011).

PBIS and SEL implementation may have been strengthened by having personnel with mental health expertise (for example school social work and school psychology) participate in the universal team. It is possible that this representation was more likely because these initiatives were being integrated with SBMH. In our 
experience with schoolwide PBIS, school social workers and other school-based mental health professionals (SBMHP) are not always a part of the universal prevention team. There is evidence that students benefit from the expertise provided by SBMHP (Franklin et al, 2009). PBIS implementation may have been strengthened by the integration of social and emotional learning objectives that were beyond typical expectations of respect and responsibility. The team's ability to make decisions about changes to its core social, emotional, and behavioral instruction in the high school case example were guided by both teacher reports of behavior (for example ORDs) and students' internalized perceptions of mental health (such as Signs of Suicide). Although the team was not working directly with the state RTI project, it was in consultation with coaches who were providing guidance on the process of implementation. This may be one reason why academic data for progress monitoring (such as CBMs) were included as part of the early intervention team's took kit.

Finally, the school improvement plan was the intersection for all the models being implemented in the case example. By reviewing the systems, practices, and data needed to address the specified outcomes, the school improvement planning processes may have led to a more braided approach (Atkins, 2010; Mcintosh ef al, 2010). By using school improvement as a guiding framework, all interventions were being led by outcomes that would benefit all students (Atkins, 2010).

As would be expected, many of the schools reported implementing practices for supporting students who were at risk. Strategies that could improve student engagement (Simonsen ef al, 2008; Walberg et al, 2004) were reported by several of the schools. While it is encouraging to see that these schools were implementing these approaches, it would be expected that they would implement these initiatives as part of an SBMH project. Systems and data are necessary to mainfain practices over time (Sugai ef al, 2010). Practices of SBMH might have been enhanced by use of other interventions including use of schoolwide teams, administrative support, universal screening, progress monitoring, and evidenced-based interventions. More research on the impact of integrating interventions on the practice of SBMH is needed. The use of guiding questions such as those used by PLCs may hold promise for integrating the systems, practices, and data for tiered models of support.

Certainly there are limitations to the current project. First, actual levels of the fidelity of implementation of interventions were not available to be incorporated in the analyses. There were limited data on the reliability and validity of the outcomes reported by the schools. These data were based on self-report from school staff and not on direct observation, which may have produced bias for the scenarios.

With these limitations in mind, the experience in this one state may shed light on integration of supports to improve outcomes for all students. Future research should pay more attention to fidelity and outcome data in order to determine the true effects of an intervention. The reliability and validity of these data collected during the intervention should be investigated.

\section{Conclusion}

Schools are faced with the multiple demands of students with complex needs, and the variety of responses to these issues. Researchers and practitioners should encourage integration of SBMH with other prevention approaches when possible, as this integration may lead to increased effectiveness of teams to provide 'depth in defense' when preventing and responding to student needs. This process will certainly take time, and it will require collaboration. As an engineer once explained regarding the development of a product:

First we make things work, then we make them work better, and then we make them more efficient.

It is our hope that this paper provides useful direction for improving this process of integration.

\section{Address for correspondence}

Hank Bohanon, Loyola University of Chicago, $820 \mathrm{~N}$. Michigan Ave., Chicago, IL 60611 , USA. Email: Hank Bohanon (hbohano@luc.edu).

\section{References}

Algozzine B, Wang C \& Violette AS (2011) Reexamining the relationship between academic achievement and social behavior. Journal of Positive Behavior Interventions 13 (1) 3-16.

Aselfine RH (2004) An outcome evaluation of the SOS Suicide Prevention Program. American Journal of Public Health 94 (3) 446-51.

Atkins MS (2010) Toward the integration of education and mental health in schools. Administration and Policy in Mental Health 37 (1-2) 40-7. 
Bohanon $\mathrm{H}$, Fenning $\mathrm{P}$, Hicks $\mathrm{K}$ et al (in press) Case example of the implementation of schoolwide positive behavior support in a high school setting. Preventing School Failure.

Bohanon H \& WU M (2011) Social and emotional learning in context with positive behavior interventions and support and response to intervention. MS submitted for publication.

Bradshaw CP, Mitchell MM \& Leaf PJ (2010) Examining the effects of schoolwide positive behavioral interventions and supports on student outcomes results from a randomized controlled effectiveness trial in elementary schools. Journal of Positive Behavior Interventions 12 (3) 133-48.

Costello EJ (2003) Prevalence and development of psychiatric disorders in childhood and adolescence. Archives of General Psychiatry 60 (8) 837-44.

Doorman C \& Castillo J (producer) (2011) Problem solving and response to intervention SAPSI training [Podcast]. www.signetwork.org/content_pages/143.

Dowdy E, Ritchey K \& Kamphaus RW (2010) Schoolbased screening: a population-based approach to inform and monitor children's mental health needs. School Mental Health 2 (4) 166-76.

DuFour R, DuFour R, Eaker R \& Karhanek G (2004) Whatever it Takes: How professional learning communities respond when kids don't learn. Bloomington: Solution Tree.

Durlak JA, Weissberg RP, Dymnicki AB, Taylor RD \& Schellinger KB (2011) The impact of enhancing students' social and emotional learning: a meta-analysis of schoolbased universal interventions. Child Development 82 (1) 405-32.

Elias MJ, Zins JE, Graczyk PA \& Weissberg RP (2003) Implementation, sustainability, and scaling up of social-emotional and academic innovations in public schools. School Psychology Review 32 (3).

Feigenberg LF, Watts CL \& Buckner JC (2010) The School Mental Health Capacity Instrument: development of an assessment and consultation tool. School Mental Health 2 (3) 142-54.

Fiks AG \& Leslie LK (2010) Portnership in the treatment of childhood mental health problems: a pediatric perspective. School Mental Health 2 (2) 93-101.

Fleming C, Haggerty K, Catalano R ef al (2005) Do social and behavioral characteristics targeted by preventive interventions predict standardized test scores and grades? Journal of School Health 75 (9) 342-9.

Forman SG, Olin SS, Hoagwood KE, Crowe M \& Saka N (2009) Evidence-based intervention in schools: developers' views of implementation barriers and facilitators. School Mental Health 1 (1) 26-36.

Foster S, Rollefson M, Doksum T et al (2005) School Mental Health Services in the United States, 2002-2003.

Rockville, MD.

Franklin C, Kim JS \& Tripodi SJ (2009) A meta-analysis of published school social work practice studies: 1980 2007. Research on Social Work Practice 19 (6) 667-77.

Horner RH, Sugai G, Smolkowski K ef al (2009) A randomized, wait-list controlled effectiveness trial assessing school-wide positive behavior support in elementary schools. Journal of Positive Behavior Interventions 11 (3) 133-44.

Kahne JE, Sporte SE, de la Torre M \& Easton JQ (2008) Small high schools on a larger scale: the impact of school conversions in Chicago. Educational Evaluation and Policy Analysis 30 (3) 281-315.

Kofter J (1995) Leading change: why transformation efforts fail. Harvard Business Review 73 (2) 59-67.

Kurns S \& Tilly WD (2008) Response to intervention blueprints: school building level edition. 78. www. nasdse.org/Portals/0/SCHOOL.pdf.

Langley AK, Nadeem E, Kataoka SH, Stein BD \& Jaycox $L H(2011)$ Evidence-based mental health programs in schools: barriers and facilitators of successful implementation. School Mental Health 2 (3) 105-13.

Lassen SR, Steele MM \& Sailor W (2006) The relationship of school-wide positive behavior support to academic achievement in an urban middle school. Psychology in the Schools 46 (6) 701-12.

Lippmann R, Ingols K, Scott $C$ ef al (2011) Validating and restoring defense in depth using attack graphs. http://extwebprod.Il.mit.edu/mission/communications/ ist/publications/061023_Lippmann.pdf.

Lueck C \& Kelly M (2010) School Based Mental Health in Illinois: Assessing the present and looking toward the future. Chicago, IL: The Illinois Children's Mental Health Partnership.

Mclntosh K, Goodman S \& Bohanon H (2010) Toward true integration of academic and behavior response to intervention systems Part 1: Tier 1 support.

Communiqué 39 (2).

Patton M (1980) Qualifative Evaluation Methods. Beverly Hills, CA: Sage.

Riley-Tillman TC, Christ TJ et al (2011) The impact of observation duration on the accuracy of data oblained from direct behavior rating (DBR). Journal of Positive Behavior Interventions 13 (2) 119-28. 
Safran SP (2006) Using the Effective Behavior Supports Survey to guide development of schoolwide positive behavior support. Journal of Positive Behavior Interventions 8 (1) 3-9.

Scott TM (2001) A schoolwide example of positive behavioral support. Journal of Positive Behavior Interventions 3 (2) 88-94.

Simonsen B, Fairbanks S, Briesch A, Myers D \& Sugai G (2008) Evidence-based practices in classroom management: considerations for research to practice 1. Education and Treatment of Children 31 (3) 351-80.

Sugai G, Horner RH, Algozzine R et al (2010) Schoolwide Positive Behavior Support: Implementers' blueprint and self-assessment. Eugene, OR: University of Oregon.

Walberg HJ, Zins JE \& Weissberg RP (2004) Recommendations and conclusions: implications for practices, training, research, and policy. In: JE Zins, RP Weissberg, MC Wang \& $\mathrm{H}$ Walberg (Eds) Building
Academic Success on Social and Emotional Learning: What does the research say? New York, NY: Teachers College Press.

Walker HM (2010) Commentary: Facilitating collaborative partnerships with schools: it's where you get it. School Mental Health 2 (2) 102-3.

Walker HM, Horner RH, Sugai G et al (1996) Integrated approaches to preventing antisocial behavior patterns among school-age children and youth. Journal of Emotional and Behavioral Disorders 4 (4) 194-209.

Weist M, Lever N, Stephan S et al (2009) Formative evaluation of a framework for high quality, evidence. based services in school mental health. School Mental Health 1 (4) 196-211.

Welsh M, Parke RD, Widaman K \& O'Neil R (2001) Linkages beiween children's social and academic competence: a longitudinal analysis. Journal of School Psychology 39 (6) 463-82. 